\title{
Trust and Skepticism in Dynamic Tension: Concepts and Empirical Refinements From Research on the Mountain Pine Beetle Outbreak in Alberta, Canada
}

\author{
John R. Parkins ${ }^{1}$ \\ Department of Resource Economics and Environmental \\ Sociology, University of Alberta, Edmonton, Canada \\ Bonita L. McFarlane \\ Natural Resources Canada, Canadian Forest Service, \\ Edmonton, Alberta, Canada
}

\section{Abstract}

Drawing on published research involving public trust and environmental risk regulation, this study explores a differentiated view of trust that includes aspects of uncritical trust, critical trust, distrust and cynicism. Using survey research of residents $(n=1,303)$ in three mountain pine beetle affected regions of Alberta, Canada, we examine the attributes of research participants who are grouped into these four types of trust and argue that critical trust relates to a category of citizenship that is ideally important for the effective functioning of democratic society. In contrast to research that draws a strong connection between public trust and public satisfaction with resource management decisions, this study identifies several subtle but significant differences in these terms, calling for more careful attention to trust-related concepts as they are utilized in research and practice.

Keywords: civic engagement, democratic decision-making, public participation, resource management, risk analysis

\section{Introduction}

Efforts to cultivate public trust in natural resource management are often identified as a key goal in achieving public acceptance of natural resource policy and management options (Mackenzie \& Larson, 2010; Shindler et al.,

1 Corresponding author: jparkins@ualberta.ca. 
2009; Toman et al., 2011; Vaske et al., 2007; Winter et al., 2004). As an example, Olsen and Shindler state that "trustworthy relations, developed well before the fire occurs, are significant to bringing agency personnel and citizens together to agree on a course of action after a fire" (2010, p. 137). Within the private sector, public trust is also linked to the social contract or social license to manage public resources (Shindler et al., 2002; Wang, 2005). Current work in this field of study is exemplified by Sharp et al. (2013), who articulate important analytical distinctions between trust and trustworthiness and demonstrate the conditions under which resource management agencies can foster trust-building activities with various publics as a long-term goal. Similarly, Lijeblad et al. (2009) identify several attributes of trust that are instrumental in achieving public trust in land management decision-making. Toward this end, scholarship on trust and resource management is often concerned with identifying the conditions that allow for the effective implementation of policies and practices within a context of social responsibility and social acceptability. Natural resource practitioners are focused on improving communications, building relations and institutional reputations in order to increase the public's trust in the activities of management agencies, and these efforts at achieving public trust and social acceptability are often conflated.

In contrast with this positive view of trust, however, another area of literature addresses the limitations of public trust as a policy and management objective. Democratic theorists such as Mark Warren make a broad claim that distrust is an important element of the democratic process in that distrust offers a basis for "the healthy suspicion of power upon which the vitality of democracy depends" (Warren, 1999, p. 310). Within the environmental management literature, research is also focused on the need for a more nuanced and differentiated view of trust, examining the crucial components of trust and distrust that are relevant to questions of public participation, public scrutiny, critical inquiry, and informed decision-making. Trettin and Musham (2000, p. 412), for example, claim that "trust may no longer be possible or desirable and quite possibly is not a realistic goal" within the context of environmental risk communication. Equally, this critical perspective on trust is taken up within a resource management context (Parkins, 2010) where high levels of interpersonal trust are found to be entirely unhelpful in fostering small group citizen engagement. Similarly, Smith et al. (2013a, p. 16) discovered that "individuals who easily trust others were less likely to be involved in resource-related management actions." In recognizing this recurring and negative relationship between a high degree of trust and robust citizen engagement, Poortinga and Pidgeon (2003) call for a more nuanced typology of trust in the context of risk regulation that exists along a continuum of trust and distrust. At the middle range of this continuum these authors define a preferred type of "critical trust" that has advantages in terms of maintaining a degree of public interest or scrutiny about matters of public concern. This 
critical trust element offers value within a resource management context because it indicates a critically engaged type of citizen in contrast to a citizen who is simply and blindly trusting. When critical trust is present, citizens are more trusting of the processes and institutions of resource management while at the same time calling attention to alternative points of view, critically engaging in discussion and debate about resource management options, and generally pushing for better or more optimal management solutions. Achieving this level of critical trust is therefore recommended as a preferred solution for involved citizens within a functioning democracy (Warren, 1999). Moreover, with this more nuanced understanding of trust, it becomes difficult to draw a direct connection between a citizen who is trusting and a citizen who is accepting of certain management practices or policy decisions; public trust and social acceptability are not necessarily the same thing.

Drawing on this differentiated view of trust, this paper offers a typology of trust that is developed from the published literature and an empirical analysis of trust within a natural resource management setting. The data set is derived from a survey of citizens who are facing issues of trust and risk regulation in relation to a mountain pine beetle (MPB) (Dendroctonus ponderosae Hopkins) outbreak that has spread east into Alberta across the Rocky Mountains from the neighboring province of British Columbia, Canada. In deductive fashion we delineate a trust typology that is based on published literature and discuss how this typology is operationalized within our study. Then in more inductive fashion we explore the dimensions of trust that emerge from our empirical findings.

Consistent with other published research (e.g., Poortinga \& Pidgeon, 2003), we find two dimensions of trust (general trust and skepticism) that are useful in understanding citizen perspectives on trust. We also find that words such as "trust" and "satisfaction" on a questionnaire have subtle but significant differences in meaning for survey participants. Implications from this analysis call for the development of more robust trust typologies in research and careful attention to the attributes of citizens that are associated with critical trust.

\section{Contextualizing trust}

Before we explore conceptual elements of trust, it is important to discuss briefly a conceptual basis for trust, and answer a basic question that undergirds this study. Why such an intensive focus on trust in resource management settings? We see three reasons for this focus. First, for a long time, resource management agencies have recognized that engaged citizenship often leads to better decisionmaking, where scientists, citizens, and policymakers can work together on complex issues and arrive at optimal solutions (Daniels \& Walker, 1996; Tanz \& Howard, 1991). Second, in contrast with a "knowledge deficit model" of citizen 
engagement, where lay citizens need to be educated before they can effectively participate in decision-making, scholars recognize that public participation is more about bringing diverse modes of thinking, attitudes, and values into a decision-making process (Árvai, 2014; Sturgis \& Allum, 2004). These arguments are clearly exhibited in popular notions of post-normal science (Funtowicz \& Ravetz, (1993) and public rationality (Slovic, 2000) where lay involvement and perspectives are valued. In other words, when issues are marked by high levels of uncertainty, expert knowledge of a subject is less important than the processes by which diverse forms of knowledge and understanding are brought to bear on the issues. Third, in recognition of the first two points, researchers are concerned about how to achieve the required conditions for meaningful and effective citizen engagement, and a common criterion of effectiveness is trust (Halvorsen, 2003; Shindler \& Neburka, 1997). Moreover, theories of deliberative democracy are concerned with issues of inclusion and non-coercion, implying a need for diversity and openness to new ideas (Chambers, 2003); a topic to which we return later in this paper. For these reasons, the idea of trust is gaining greater attention within resource management settings, and is a focus of this paper.

\section{Conceptualizing trust}

Trust refers to a situation where something of value is held by one person for the benefit of another. In this sense trust "involves a judgement, however tacit or habitual, to accept vulnerability to the potential ill will of others by granting them discretionary power over some good" (Warren, 1999, p. 311). As a way to differentiate several dimensions of trust, Zucker (1986) identifies three specific ways in which trust is produced. Trust is process-based where an association with others generates trust through personal experience and a sense of shared history. Trust is characteristic-based where individual ethnicity or sociodemographic background provides a basis for trust. Finally, trust is also institution-based where trust is produced through institutional structures and attributes of association between individuals and groups that otherwise have no personal connection. It is this third way of producing trust that scholars claim to be the most important within contemporary society. We are faced with a world of complex management challenges that requires social coordination and levels of institutional trust to manage such things as water treatment facilities, airline travel, and forest health. In the words of Luhmann, "the very complexity of the social order creates a greater need for coordination and hence a need to determine the future - i.e., a need for trust, a need which is now decreasingly met by familiarity" (1979, p. 20).

This lack of familiarity speaks to the growing institutional basis for producing trust and what some scholars identify as "social trust" (Siegrist, 2000; Siegrist \& 
Cvetkovich, 2000). Within an institutional context, "social trust is employed to select experts who are trustworthy and whose opinions can be believed as being accurate" (Siegrist \& Cvetkovich, 2000, p. 714). Social trust is the willingness to rely on those who have responsibility for making decisions and taking actions related to the management of technology, the environment, medicine, or other realms of public health and safety. The people being trusted are those within organizations who may not be personally known to the individual making the trust attribution (Siegrist et al., 2000). One of the most important factors affecting social trust is the perception that the agency and people representing the agency share similar values as the public (Smith et al., 2013a). When individuals perceive that their opinions and values are reflected in an agency's planning and management efforts they are more likely to trust the agency and support management actions (Needham \& Vaske, 2008; Siegrist et al., 2000; Smith et al., 2013a).

Social trust may be particularly important in situations where the public lacks knowledge. When the public lacks sufficient knowledge for making risk assessments and acceptability judgments, they trust the judgments of experts and management agencies to do the right thing. Public reactions and acceptance of new technologies, for example, are guided by social trust and the confidence people have in companies and government agencies (Siegrist et al., 2000, p. 355). Similarly, satisfaction with management responses to new threats to forest ecosystems may be based on a degree of trust in government. This concept of trust in government has a distinctive institutional basis and a future orientation, as compared to other ways in which trust is produced and situated at the interpersonal level. Therefore, the concept of institutional trust is taken up in this study as a starting point for understanding a multifaceted notion of trust in contemporary society.

Drawing on a multifaceted understanding of institutional trust, authors such as Poortinga and Pidgeon (2003) as well as Renn and Levine (1991) identify several core components of trust that include perceived competence (the degree of technical expertise), objectivity (absence of bias), fairness (degree that all relevant points of view are taken into account), consistency (predictability of ideas and behavior based on past experience), and faith (the goodwill that is expressed within the trusting relationship). Added to these components, the work of Kasperson et al. (1992) also offers four components of trust: commitment, competence, caring, and predictability, which map onto the five components from Renn and Levine (1991). This differentiated view of trust, where multiple factors are thought to have a distinctive role in the way that trust manifests within society is understood by these authors to have merit in terms of providing a conceptually rich framework for research. 
Researchers also note, however, that the empirical evidence is quite limited in terms of uncovering and confirming these multiple components of trust. In spite of efforts to develop a more complex empirical model, previous work has often arrived at two-factor solutions. Frewer et al. (1996) found one factor related to general trust and another factor related to care. Metlay (1999) found one factor related to general trust and another factor related to competence. Earle and Cvetkovich (1995) identify factors related to agreement and sympathy, and more recently Poortinga and Pidgeon (2003) found one factor related to general trust and another factor related to skepticism. Although the work of Smith et al. (2013b) and Lijeblad et al. (2009) represents more recent findings of trust components relative to land management, in this study we are particularly interested in the two-factor model and trust typology put forward by Poortinga and Pidgeon (2003) because of the way it draws on notions of distrust that are central to the analytic framework for this research. This typology results in four distinct types of trust that are identified in Figure 1.

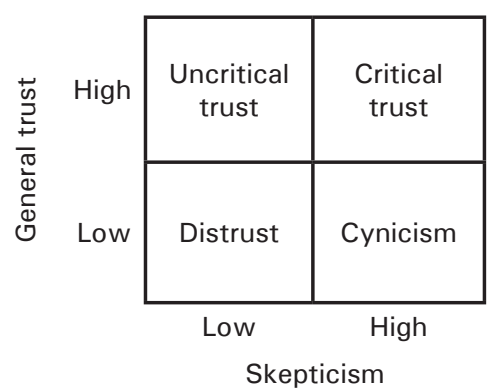

Figure 1. A conceptual typology of trust

Source: Adapted from Poortinga and Pidgeon (2003); used with permission.

From this typology we point out that notions of distrust, critical trust, and cynicism are not the same thing. From a public policy point of view, achieving uncritical trust (high general trust and low skepticism) is a common objective in terms of getting policies implemented with the least amount of friction. Democratic theorists and practitioners, however, point to the value of critical trust (high general trust and high skepticism), as a counterpoint to apathy, disinterest, and uncritical acceptance that can be associated with public policy choices.

These conceptual advances are an important part of the literature on trust and environmental risk regulation in western countries. There is less empirical analysis, however, on the attributes of individuals who are aligned with these four types of trust. We know little about the characteristics associated with people who, for instance, have high levels of general trust and skepticism versus people who have low levels of general trust and skepticism. We also 
do not know much about how these types are distributed within the general population and the linkages to other factors such as awareness of resource management options, level of dependence on the local resource in question, general educational background, and so on. This study offers some insight into these relationships. It also offers insight into the dimensions of trust that are reflected in survey statements like "I trust the government" and "I am satisfied with management actions." As a starting point for this analysis, the next section provides an overview of the MPB outbreak in Alberta.

\section{Mountain pine beetle in Alberta}

Alberta is a resource-rich province with a high-profile energy industry most notably linked to the oil sands region, the third-largest proven oil reserves in the world. The province is dominated by the energy industry, but it has several strong primary industries including agriculture, forestry, and mining. Not without controversy in many circles of influence (e.g., Timoney \& Lee, 2001), the provincial government enjoys relatively favorable standing with Alberta citizens, who have one of the highest standards of living in Canada, and who have elected the same politically conservative government into office since 1971. Given the prominent culture of resource management, dependence on these industries for wealth creation, and familiarity with resource management decisions, this broader sociopolitical context offers an important backdrop to issues of public perception regarding the MPB in Alberta.

The MPB is endemic to the lodgepole pine (Pinus contorta Dougl. ex Loud. var. latifolia Englem.) forests of western North America. Since the 1990s, however, the beetle has increased in population and spread beyond its historical range, affecting most of the western United States, southern British Columbia, and eastern Alberta. In British Columbia alone, the beetle has infested 18.1 million hectares and killed a cumulative total of 710 million cubic meters of timber (MFLNRO, 2012) and is predicted to have significant long-term economic impacts in the province (Patriquin et al., 2007). In addition, the beetle is impacting watersheds, wildlife habitat, carbon storage, forest fire risk, and recreation (ASRD, 2007b; Nealis \& Peter, 2008). In the neighboring province of Alberta, the expansion of local endemic populations and overflights from British Columbia in 2006 and 2009 have extended the MPB to areas of the province with no prior history of the beetle. In addition to spreading to new areas, the beetle appears to be able to adapt to other species such as jack pine (Pinus banksiana Lamb.), a predominant species in much of Canada's boreal forest (Safranyik et al., 2010).

As the beetle spreads, scientists and land managers are faced with the challenge of formulating management actions and strategies with uncertainty of the beetle's biology and ecology in these new habitats. Although significant progress 
is being made in the scientific understanding of this unprecedented epidemic, much uncertainty remains regarding the effectiveness of treatment options and the persistence of the beetle, especially in the boreal forest. In response to the MPB infestation in Alberta, the provincial government department responsible for forest management on provincial crown lands has developed a management strategy and action plan aimed at containing and minimizing the infestation along the eastern slopes of the Rocky Mountains and preventing spread of the beetle into the boreal forest (ASRD, 2007a, 2007b). Because this land is largely publicly owned, public acceptance of management strategies is critical to effective MPB management (Shindler et al., 2002).

The rapid pace of the MPB outbreak has resulted in management agencies having little time to solicit public input and incorporate local concerns into the management response, or to educate the public about management intentions and interventions (Mackenzie \& Larson, 2010). Thus, during periods of rapid infestation, the public may have little choice but to rely on the judgments of experts, trust management agencies, and accept their response. Given these details, the MPB outbreak in Alberta offers an interesting opportunity to explore dimensions of trust and public land management in the context of environmental risk.

\section{Survey research methods}

Survey data were gathered from a sample of residents of the western forested area of Alberta. Using a stratified sampling approach the area was divided into three study regions representing different MPB histories. The southwest region has a history of MPB outbreaks dating back to the 1940s and was experiencing an outbreak at the time of the study. The west-central region had no history of MPB and no outbreak during the study period but had high potential for beetle population growth. The northwest region also had no history of the beetle but was experiencing a large outbreak as a result of a dispersal of beetles from British Columbia in 2006. More details on the study regions can be found in McFarlane et al. (forthcoming). Several management options were being used by the provincial government to control the beetle on provincial crown lands in the regions: single-tree treatments such as cut and burn, harvesting areas of infested trees and processing the trees to kill the beetles, forest industry adjusting harvest plans to log healthy but susceptible areas before they were attacked, and prescribed burning.

Residents were recruited by telephone to participate in a mail survey. Of the 5,647 residents who were contacted, 1,994 agreed to participate in the mail survey: 643 from the southwest, 649 from the west-central, and 702 from the northwest. The initial survey package was mailed in September 2009, followed 
by a reminder postcard two weeks later and another survey package about six weeks after the initial mailing. A total of 1,303 questionnaires were returned, representing an overall mail survey response of 66 percent (\%) (74\% for the southwest, $66 \%$ for the west-central, and $59 \%$ for the northwest); and an overall response of $23 \%$ based on the initial telephone contacts.

The questionnaire assessed perceptions of MPB impacts, attitude toward the $\mathrm{MPB}$, acceptability of management options, satisfaction with response to the beetle, trust in government and the forest industry, awareness of MPB and its management, sources of MPB information, and several demographic attributes of survey participants. A subset of these variables was used in the analysis. We assessed general trust using statements related to commitment, openness, fairness, competence, and faith regarding the provincial government. Skepticism was assessed using statements related to vested interest of the forest industry and credibility of the provincial government (Table 1).

In addition to these survey items, we included statements in the questionnaire that are more direct in the use of "trust" wording as well as a measure of the level of public "satisfaction" with MPB interventions. In contrast to the indirect ways in which the concept of trust is taken up within survey items reported in Table 1, these additional survey statements are more direct in their language. For example:

- I trust the provincial government to implement a responsible and effective MPB management program

- I am satisfied with the provincial government's response to the MPB.

When survey participants read these statements, we assume they reflect a degree of happiness or acceptance with a management strategy or a decision to the extent that the public is not concerned and will understand the situation to be uncontroversial. If this is the case, these survey statements offer an opportunity to explore the multifaceted nature of trust within the context of MPB management in Alberta. Trust statements were rated on a scale of 1 to 5, 1 being strongly disagree and 5 being strongly agree, with a no opinion option. Other survey items are also included in the analysis to follow.

Respondents rated their awareness of MPB management in their region on a 4-point scale: 1 = not aware of it, 2 = little knowledge, 3 = moderate knowledge, and $4=$ well informed. To examine perceived values similarity, respondents rated the statement "I feel the response to the mountain pine beetle reflects my values and opinions" on a scale of $1=$ strongly disagree to $5=$ strongly agree, with a no opinion option. Satisfaction with the provincial government response to the beetle was assessed on a scale of $1=$ very dissatisfied to $5=$ very satisfied, with a no opinion option. Being female, having a household member 
dependent on the forest industry for their economic livelihood, and having a post-secondary education were treated as dummy variables whereby $0=$ no and 1 = yes. Confirmatory factor analysis of trust statements was conducted with Lisrel ${ }^{\circledR}$ 8.8. Other data analysis was conducted using SAS ${ }^{\circledR}$ 9.3.

\section{Results}

\section{Descriptive statistics and confirmatory factor analysis}

Examining the trust statements in Table 1, mean scores and standard deviations provide insights on the general trends within survey responses. Respondents tend to agree $(M>3.0)$ that the government is committed to reducing the impact of MPB, is open to new ideas and alternative points of view, has the necessary expertise to manage the beetle effectively, and is too influenced by the forest industry regarding MPB. There is slightly less agreement $(M \sim 3.0)$ for the idea that the government considers all relevant points of view in managing MPB, and significantly more agreement that MPB control is in the best interest of Albertans $(M>4.0)$. There was disagreement that government information about the MPB tends to be biased and one-sided $(M<3.0)$.

\section{Table 1. Confirmatory factor analysis of trust statements relating to mountain pine beetle in Alberta, Canada}

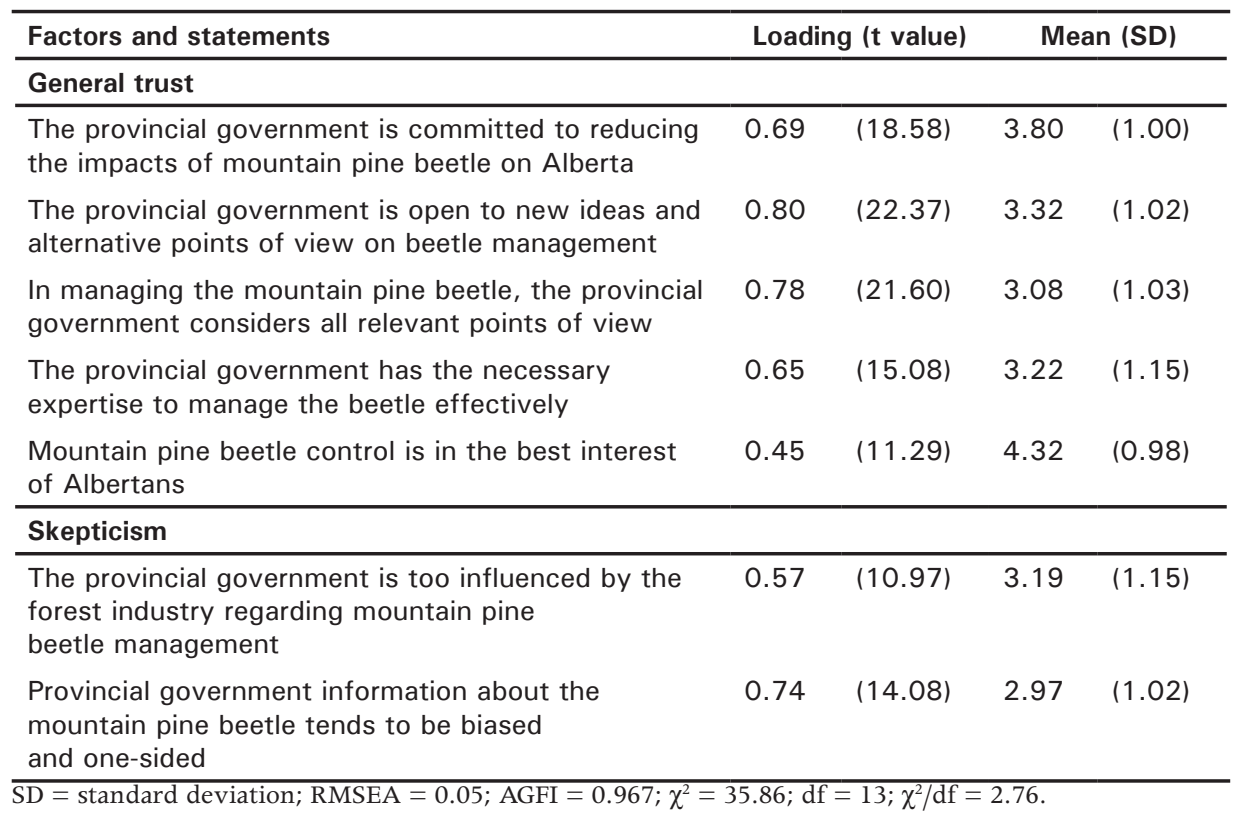

Turning to the factor analysis, we tested Poortinga and Pidgeon's (2003) twofactor model of general trust and skepticism. Fit criteria for the two-factor model 
indicate a good fit $(\mathrm{RMSEA}=0.05 ; \mathrm{AGFI}=0.97 ; \chi=35.86 ; \mathrm{df}=13 ; p=0.0006$; $\chi 2 / \mathrm{df}=2.76$ ). These two factors are used in subsequent analysis described below as an empirical and analytical basis for developing the trust typology conceptualized in Figure 1.

\section{Trust types}

To create a typology of trust we calculated scores for the general trust and skepticism factors for each respondent by summing the ratings of the statements that loaded on the factor. Next, we used the SAS FASTCLUS procedure to produce four discrete, non-overlapping clusters based on the summed factor scores. Finally, we calculated mean factor scores for each cluster and used Poortinga and Pidgeon's (2003) conceptual typology as a guide in naming the clusters. About $16 \%(n=204)$ of respondents could not be classified because of missing values on at least one of the general trust or skepticism statements and were removed from further analysis. Of respondents who were classified, the Critical and Uncritical trust clusters each represent about $36 \%$ of respondents and the Cynicism and Distrust clusters represent about $8 \%$ and $20 \%$ of respondents, respectively (Table 2). Respondents in the Uncritical cluster have high general trust and low skepticism in regard to the government's management of MPB and therefore are likely to accept the government's information and decisions. Critical trust respondents have moderate general trust combined with moderate skepticism suggesting that although respondents in this category may trust the government they are also likely to question the government's MPB information and management decisions. The Cynicism cluster has the lowest trust of government in managing the MPB and highest skepticism about the government's intentions. Poortinga and Pidgeon (2003) refer to this as deep distrust and suggest the Cynicism category represents a rejection of everything that comes from government. Although the Distrust cluster also has low general trust and high skepticism this cluster is not as distrusting and skeptical as the Cynicism cluster. Descriptive statistics show that about $70 \%$ of respondents in the four clusters had a post-secondary education, $42 \%$ were female, $62 \%$ had moderate knowledge or were well informed about MPB management in their region, and $20 \%$ had a household member dependent on the forest industry for their economic livelihood. About 49\% trust the provincial government to implement a responsible and effective MPB management program, about 53\% were somewhat or very satisfied with the provincial government response, and about $44 \%$ felt the response reflected their values and opinions. 
Table 2. Characteristics of the trust clusters

\begin{tabular}{lcccc}
\hline & \multicolumn{3}{c}{ Cluster } \\
& Uncritical & Critical & Cynicism & Distrust \\
\hline $\begin{array}{l}\text { Respondents } \\
\text { number (\%) }\end{array}$ & $368(35.79)$ & $373(36.28)$ & $82(7.97)$ & $205(19.94)$ \\
$\begin{array}{l}\text { General trust score } \\
M \text { (SD) }\end{array}$ & $4.27(0.29)^{\mathrm{a}}$ & $3.52(0.23)^{\mathrm{b}}$ & $1.73(0.36)^{\mathrm{c}}$ & $2.77(0.23)^{\mathrm{d}}$ \\
& & & & \\
Skepticism score $^{1}$ & $2.48(0.79)^{\mathrm{a}}$ & $3.18(0.62)^{\mathrm{b}}$ & $4.19(0.83)^{\mathrm{c}}$ & $3.48(0.80)^{\mathrm{d}}$ \\
$M$ (SD) $^{\mathrm{N}}$ & & & & \\
\hline
\end{tabular}

\footnotetext{
${ }^{1}$ Rated on a scale from $1=$ strongly disagree to $5=$ strongly agree. Any two means in a row that do not share a letter are significantly different at $p<0.05$ according to the Tukey-Kramer test. $M(\mathrm{SD})=$ mean (standard deviation).
}

Table 3 indicates there are differences among the clusters based on trust in the provincial government, satisfaction with management response to MPB, values similarity, awareness of MPB management, and demographics. The Uncritical cluster shows greater trust in the provincial government to implement a responsible and effective MPB management program, are more satisfied with the provincial government response to the beetle, are better informed about MPB management in their region, and show higher agreement that the response reflects their values and opinions than the other trust types. Although the Critical cluster also trusts the provincial government to implement a responsible and effective MPB management program, are satisfied with the provincial government response to the beetle, and view the response as reflecting their values and opinions, they rate these variables near neutral $(M=3.0)$ and significantly lower than the Uncritical cluster and higher than the Distrust and Cynicism clusters. These results and the moderate scores on general trust and skepticism suggest that the Critical cluster represents a moderate group between those who are very satisfied and trusting and those who are distrusting and cynical. As theory on trust and democracy would suggest, this group might be more likely to engage as citizens in natural resource management participatory processes.

Both the Distrust and Cynicism clusters do not trust the government to implement a responsible and effective MPB management program, are dissatisfied with the provincial government response to the beetle, and do not view the response as reflecting their values and opinions. The Distrust cluster scored lower than the other groups on these variables. The four clusters do not differ on age and sex but there are significant differences for education with the Distrust and Cynicism clusters having a higher percentage with a post-secondary education. 
Table 3. Means (standard deviations) ${ }^{1}$ of attributes of a trust typology for management of mountain pine beetle

\begin{tabular}{|c|c|c|c|c|}
\hline Attributes & $\begin{array}{c}\text { Uncritical } \\
\text { trust }\end{array}$ & Critical trust & Cynicism & Distrust \\
\hline $\begin{array}{l}\text { Trust: } \\
\text { I trust the provincial } \\
\text { government to } \\
\text { implement a responsible } \\
\text { and effective MPB } \\
\text { management program }{ }^{2}\end{array}$ & $3.99(0.86)^{a}$ & $3.11(1.00)^{b}$ & $1.59(0.88)^{\mathrm{C}}$ & $2.26(1.07)^{d}$ \\
\hline $\begin{array}{l}\text { Satisfaction: } \\
\text { Satisfaction with the } \\
\text { provincial government } \\
\text { response }^{3}\end{array}$ & $3.89(0.85)^{a}$ & $3.25(1.02)^{b}$ & $2.17(1.10)^{\mathrm{C}}$ & $2.77(1.02)^{d}$ \\
\hline $\begin{array}{l}\text { Values similarity: } \\
\text { I feel the response } \\
\text { to the mountain pine } \\
\text { beetle reflects my } \\
\text { values and opinions }^{2}\end{array}$ & $3.84(0.85)^{a}$ & $3.21(0.85)^{b}$ & $1.96(1.06)^{\mathrm{C}}$ & $2.68(1.03)^{d}$ \\
\hline $\begin{array}{l}\text { Awareness: } \\
\text { Moderate or high } \\
\text { awareness of MPB } \\
\text { management }^{4}(\%)\end{array}$ & 71.31 & 55.71 & 59.76 & 58.33 \\
\hline Demographics & & & & \\
\hline Age in years & $52.54(13.44)$ & $50.14(12.52)$ & $50.18(12.14)$ & $50.33(13.87)$ \\
\hline Female (\%) & 43.21 & 43.97 & 40.24 & 39.02 \\
\hline $\begin{array}{l}\text { Post-secondary } \\
\text { education }{ }^{4}(\%)\end{array}$ & 66.47 & 68.97 & 84.00 & 75.92 \\
\hline $\begin{array}{l}\text { Forest industry - } \\
\text { dependent household } \\
\text { member }(\%)\end{array}$ & 21.39 & 17.71 & 22.78 & 20.10 \\
\hline
\end{tabular}

${ }^{1}$ Any two means in a row that do not share a letter are significantly different at $p<0.05$ according to the Tukey-Kramer test; ${ }^{2}$ rated on a scale from $1=$ strongly disagree to $5=$ strongly agree; ${ }^{3}$ rated on a scale from $1=$ very dissatisfied to $5=$ very satisfied; ${ }^{4}$ significantly different at $p<0.05$ based on $\chi^{2}$ test of independence.

\section{Exploring differences between trust and satisfaction}

In examining the link between the deeper meanings of terms like trust and satisfaction in this study, we used ordinary least squares regression to uncover these insights. Descriptive statistics for key variables are provided in Table 4, and they include the two trust factors (generalized trust and skepticism), values similarity, awareness of MPB, and satisfaction with MPB management. First, we regressed the trust statement (I trust the provincial government ...) on the two trust factors, values similarity, awareness, and demographics (age, sex, education, and forest dependence) (Table 5; Model 1). General trust, skepticism, and values similarity have significant beta coefficients. As expected, 
general trust and values similarity have a positive influence and skepticism has a negative association with the trust statement. None of the demographic variables have a significant influence on the dependent variable. The regression explained about $52 \%$ of the variance in the trust statement with an $F$ value of 100. Next, we regressed the satisfaction statement (satisfaction with provincial government response) on the same independent variables (Table 5; Model 2). Similar to the first regression, general trust and values similarity have significant beta coefficients and the direction of these relationships is consistent. The main difference between these two regression models is that skepticism is not significant and forest dependence is significant in the satisfaction model, and general trust has a larger beta coefficient in Model 1. These differences are reflected in the explained variance which is much lower for Model $2(27.4 \%$; F value $=32.28$ ).

Table 4. Distribution of variables used in regression analyses to explore factors associated with trust and satisfaction with management of mountain pine beetle

\begin{tabular}{ll}
\hline Variable & Mean (SD) \\
\hline General trust & $3.53(0.77)$ \\
Skepticism & $3.07(0.90)$ \\
Trust in provincial government & $3.14(1.23)$ \\
Satisfaction with provincial government response & $3.28(1.00)$ \\
Values similarity & $3.31(1.09)$ \\
Moderate or high awareness of MPB management (\%) & 62.06 \\
Age in years & $51.04(13.13)$ \\
Female (\%) & 42.41 \\
Post-secondary education (\%) & 70.64 \\
Forest dependent (\%) & 19.90 \\
\hline SD $=$ standard deviation. &
\end{tabular}


Table 5. Standardized ordinary least squares regression estimates of variables associated with trust and satisfaction of management of mountain pine beetle

\begin{tabular}{lcc}
\hline Independent variables & \multicolumn{2}{c}{ Dependent variables } \\
\cline { 2 - 3 } & $\begin{array}{c}\text { Model 1 } \\
\text { Trust statement }\end{array}$ & $\begin{array}{c}\text { Model 2 } \\
\text { Satisfaction statement }\end{array}$ \\
\hline General trust & $0.57^{\mathrm{a}}$ & $0.39^{\mathrm{a}}$ \\
Skepticism & $-0.13^{\mathrm{a}}$ & -0.04 \\
Value similarity & $0.13^{\mathrm{a}}$ & $0.16^{\mathrm{a}}$ \\
Awareness of management & -0.03 & 0.01 \\
Age & 0.02 & $<-0.01$ \\
Female & $<-0.01$ & 0.02 \\
Post-secondary education & $<-0.02$ & 0.03 \\
Forest dependent & -0.05 & $-0.07^{\mathrm{b}}$ \\
$n$ & 720 & 663 \\
Adjusted $R^{2}$ & 0.524 & 0.274 \\
$F$ value & $100.11^{\mathrm{a}}$ & $32.28^{\mathrm{a}}$ \\
\hline a $p \leq 0.001 ;{ }^{\mathrm{b}} p \leq 0.05$. & &
\end{tabular}

\section{Discussion}

Consistent with other research that attempts to provide a richly differentiated typology of trust, our two-factor solution is consistent with Poortinga and Pidgeon (2003), who identify general trust and skepticism as important dimensions of trust within the general population. This analysis does not necessarily discount the broader sense in which trust is inclusive of components such as trustworthiness, objectivity, consistency, and goodwill where these components may still be important conceptually in terms of public judgments about trust at institutional levels. Although other studies have used a multifactorial approach to trust (e.g., Smith et al., 2013b), we learn through this empirical work that several of the components of trust may be subsumed within one factor of "general trust" and this factor has statistical resonance with key dependent variables in this study.

Following the outcome of the two-factor solution (general trust and skepticism), our typology of trust takes this analysis further than other published research by showing how different dimensions of trust map onto questions of MPB management and several demographic variables. Analysis shows there are distinct populations of survey participants who can be classified according to four types of trust, with a large number of these participants falling into the Uncritical trust and Critical trust categories. A key distinction between Uncritical trust and Critical trust has to do with the relative levels of trust, 
satisfaction, and values similarity among those who are in the Critical trust category. Individuals in the Critical trust category are less trusting than the Uncritical trust group (with average scores a little over 3.0 (neutral) on a 5-point scale), but they remain significantly more trusting than those who are in the Distrust and Cynicism categories. In other words, individuals with critical but trusting views appear to hold a unique middle position between those who are characterized by uncritical trust on one hand and those who are distrusting and cynical on the other. Individuals in the Critical trust category respond to statements of trust, satisfaction, and values similarity in ways that are distinct from other individuals.

Referring back to the discussion of democratic theory and the expected value that critical trust holds in terms of fostering alternative points of view, critical engagement, discussion, debate, and improved decisions, one might argue that instead of seeking ever higher levels of trust between the general public and resource managers (e.g., Vaske et al., 2007), it is preferable to seek a moderate level of trust that is tempered with a degree of skepticism. Propositions made by political theorists such as Warren (1999) about the value of distrust as a democratic resource are borne out by recent research by Smith et al. (2013a) who observe that individuals who trust in resource managers are also less likely to be involved in resource management actions. In taking this position, there is recognition that citizens can also become too distrustful and too cynical, and are not likely to make valuable contributions to management and policy debates. Moreover, these categories of deep distrust are unproductive and debilitating within a resource management context, often leading to harsh conflict, legal action, and the breakdown of democratic procedures.

A middle ground, therefore, represented by critical trust holds a dynamic tension between trust and skepticism. In our survey, a sizable number of survey participants held this position (36\% of classified respondents), and one policy challenge might include finding ways to maintain trust and skepticism in balance as an objective of civic engagement processes. In more practical terms, how might one nurture individuals to hold the desirable characteristics of critical trust? This is an important question that deserves further attention within a resource management context, but insights from deliberative democracy may offer some hints. If broad representation and inclusion is a hallmark of democratic process (Chambers, 2003), then one way to maintain skepticism is to maintain and support wide-ranging and often dissenting views within a decision-making process. Instead of driving toward a final decision as efficiently as possible, more engaged citizens may need time to explore alternative points of view, wrestle with issues, and come to reasoned judgment based on insights from a range of sources and forms of expertise. Ideas along these lines are clearly 
difficult to implement against conventional wisdom, but resources are available to facilitate the practical aspects of this paper in terms of critically engaged citizenship (e.g., Gastil \& Levine, 2005).

Another source of insight from this study comes from the regression analysis and the distinctions between statements about trust and statements about satisfaction in relation to MPB management. Although the published literature on natural resource management often draws a strong connection between levels of trust and levels of satisfaction or social acceptability of management prescriptions, this analysis indicates that responses to these statements draw on different degrees of general trust and skepticism. General trust is a significant predictor of individual responses to statements about trust and satisfaction, but the magnitude of the relationship is quite different and the explained variance is much lower for the satisfaction statement. Satisfaction has a lot less to do with general trust and skepticism in this model and therefore when a person indicates that they are satisfied with a management response we have less confidence in linking this response to related factors such as trust or skepticism. In other words, this analysis indicates that we have less insight into the predictors of public satisfaction with management action and we are cautious about overdrawing a connection between social trust and satisfaction when it comes to judging public perceptions of resource management activities.

\section{Conclusion}

Within the resource management literature, public trust and public satisfaction are often conflated in ways that are not helpful. To remedy this situation, and to add to a growing body of literature on this topic, this study identifies a category of critically trusting members of the general public who are distinct from those who are uncritically trusting on one hand and entirely distrusting and cynical on the other hand. This middle ground of trusting and skeptical citizens who hold these two positions in dynamic tension can be identified empirically within a general population survey and, as argued in this paper, can make important contributions to the democratic process in resource management.

Given the relatively small sample sizes for each trust type, and the limited range of variables to identify and describe this Critical trust group, additional research on this topic can provide more insight into the characteristics of this group and the conditions under which this group can be promoted and enhanced within the general population. In the end, this study cautions against high levels of uncritical public trust as a goal of resource management and cautions against conflating notions of trust with notions of social acceptability in relation to resource management decisions. 


\section{Acknowledgments}

We thank the Foothills Research Institute, Hinton, Alberta, for their financial support of this study, and we thank David Watson for his technical assistance with the survey research.

\section{References}

Árvai, J. (2014). The end of risk communication as we know it. Journal of Risk Research, 17(10), 1245-1249. doi:10.1080/13669877.2014.919519

ASRD (Alberta Sustainable Resource Development). (2007a). Mountain pine beetle action plan (Pub. No. T/152). Retrieved from http://mpb.alberta.ca/ AlbertasStrategy/documents/MPB_action_plan.pdf.

ASRD (Alberta Sustainable Resource Development). (2007b). Mountain pine beetle management strategy (Pub. No. T/154). Retrieved from http://mpb. alberta.ca/AlbertasStrategy/documents/MPB_man_strategy.pdf.

Chambers, S. (2003). Deliberative democratic theory. Annual Review of Political Science, 6(1), 307-326.

Daniels, S. E., \& Walker, G. B. (1996). Collaborative learning: Improving public deliberation in ecosystem-based management. Environmental Impact Assessment Review, 16(2), 71-102.

Earle, T. C., \& Cvetkovich, G. T. (1995). Social trust: Toward a cosmopolitan society. Westport, CT: Praeger.

Frewer, L. J., Howard, C., \& Shepherd, R. (1996). Effective communication about genetic engineering and food. British Food Journal, 98, 48-52.

Funtowicz, S. O., \& Ravetz, J. R. (1993). Science for the post-normal age. Futures, 25(7), 739-755.

Gastil, J., \& Levine, P. (2005). The deliberative democracy handbook: Strategies for effective civic engagement in the twenty-first century. Jossey-Bass.

Halvorsen, K. E. (2003). Assessing the effects of public participation. Public Administration Review, 63(5), 535-543.

Kasperson, R. E., Golding, D., \& Tuler, S. (1992). Social distrust as a factor in siting hazardous facilities and communicating risk. Journal of Social Issues, 48(4), 161-187. 
Lijeblad, A., Borrie, W. T., \& Watson, A. E. (2009). Determinants of trust for public lands: Fire and fuels management on the Bitterroot National Forest. Environmental Management, 43(4), 571-584.

Luhmann, N. (1979). Trust and power: Two works by Niklas Luhmann. London: John Wiley and Sons.

Mackenzie, B. F., \& Larson, B. M. H. (2010). Participation under time constraints: Landowner perceptions of rapid response to the emerald ash borer. Society and Natural Resources, 23(10), 1013-1022.

McFarlane, B. L., Watson, D. O. T., \& Parkins, J. R. (forthcoming). Views of the public and land managers on mountain pine beetle activity and management in western Alberta. Edmonton, AB: Canadian Forest Service, Natural Resources Canada.

Metlay, D. (1999). Institutional trust and confidence: A journey into a conceptual quagmire. In G. T. Cvetkovich \& R. E. Lofstedt (Eds.), Social trust and the management of risk. London: Earthscan.

MFLNRO (British Columbia Ministry of Forests, Lands and Natural Resource Operations). (2012). Beetle facts. Retrieved from http://www.for.gov.bc.ca/ hfp/mountain_pine_beetle/facts.htm

Nealis, V., \& Peter, B. (2008). Risk assessment of the threat of mountain pine beetle to Canada's boreal and eastern pine forests (Inf. Rep. BC-X-417). Victoria, BC: Canadian Forest Service, Natural Resources Canada.

Needham, M. D., \& Vaske, J. J. (2008). Hunter perceptions of similarity and trust in wildlife agencies and personal risk associated with chronic wasting disease. Society and Natural Resources, 21(3), 197-214.

Olsen, C. S., \& Shindler, B. A. (2010). Trust, acceptance, and citizen-agency interactions after large fires: Influences on planning processes. International Journal of Wildland Fire, 19(1), 137-147.

Parkins, J. R. (2010). The problem with trust: Insights from advisory committees in the forest sector of Alberta. Society and Natural Resources, 23(9), 822-836.

Patriquin, M. N., Wellstead, A. M., \& White, W. A. (2007). Beetles, trees, and people: Regional economic impact sensitivity and policy considerations related to the mountain pine beetle infestation in British Columbia, Canada. Forest Policy and Economics, 9(8), 938-946.

Poortinga, W., \& Pidgeon, N. F. (2003). Exploring the dimensionality of trust in risk regulation. Risk Analysis, 23(5), 961-972. 
Renn, O., \& Levine, D. (1991). Credibility and trust in risk communication. In R.

E. Kasperson \& P. J. M. Stallen (eds), Communicating risks to the public (pp. 175-218). Norwell, MA: Kluwer.

Safranyik, L., Carroll, A. L., Régnière, J., Langor, D. W., Riel, W. G., Shore, T. L., ... Taylor, S. W. (2010). Potential for range expansion of mountain pine beetle into the boreal forest of North America. The Canadian Entomologist, $142(5), 415-442$.

Sharp, E. A., Thwaites, R., Curtis, A., \& Millar, J. (2013). Trust and trustworthiness: Conceptual distinctions and their implications for natural resources management. Journal of Environmental Planning and Management, 56(8), 1246-1265.

Shindler, B. A., Brunson, M., \& Stankey, G. H. (2002). Social acceptability of forest conditions and management practices: A problem analysis (Gen. Tech. Rep. PNW-GTR-537). Portland, OR: Pacific Northwest Research Station, USDA Forest Service.

Shindler, B., \& Neburka, J. (1997). Public participation in forest planning. Journal of Forestry, 95(1), 17-19.

Shindler, B. A., Toman, E., \& McCaffrey, S. M. (2009). Public perspectives of fire, fuels and the Forest Service in the Great Lakes Region: A survey of citizen-agency communication and trust. International Journal of Wildland Fire, 18(2), 157-164.

Siegrist, M. (2000). The influence of trust and perceptions of risk and benefits on the acceptance of gene technology. Risk Analysis, 20(2), 195-203.

Siegrist, M., \& Cvetkovich, G. (2000). Perception of hazards: The role of social trust and knowledge. Risk Analysis, 20(5), 713-720.

Siegrist, M., Cvetkovich, G., \& Roth, C. (2000). Salient value similarity, social trust, and risk/benefit perception. Risk Analysis, 20(3), 353-362.

Slovic, P. E. (2000). The perception of risk. London: Earthscan Publications.

Smith, J. W., Leahy, J. E., Anderson, D. H., \& Davenport, M. A. (2013a). Community/agency trust and public involvement in resource planning. Society \& Natural Resources, 26(4), 452-471.

Smith, J. W., Leahy, J. E., Anderson, D. H., \& Davenport, M. A. (2013b). Community/agency trust: A measurement instrument. Society \& Natural Resources, 26(4), 472-477. 
Sturgis, P., \& Allum, N. (2004). Science in society: Re-evaluating the deficit model of public attitudes. Public Understanding of Science, 13(1), 55-74.

Tanz, J. S., \& Howard, A. F. (1991). Meaningful public participation in the planning and management of publicly owned forests. The Forestry Chronicle, 67(2), 125-130.

Timoney, K., \& Lee, P. (2001). Environmental management in resource-rich Alberta, Canada: First world jurisdiction, third world analogue? Journal of Environmental Management, 63(4), 387-405.

Toman, E., Stidham, M., Shindler, B., \& McCaffrey, S. (2011). Reducing fuels in the wildland-urban interface: Community perceptions of agency fuels treatments. International Journal of Wildland Fire, 20(3), 340-349.

Trettin, L., \& Musham, C. (2000). Is trust a realistic goal of environmental risk communication? Environment and Behavior, 32(2), 410-426.

Vaske, J. J., Absher, J. D., \& Bright, A. D. (2007). Salient value similarity, social trust and attitudes toward wildland fire management strategies. Human Ecology Review, 14(2), 223-232.

Wang, S. (2005). Managing Canada's forests under a new social contract. The Forestry Chronicle, 81(4), 486-490.

Warren, M. E. (Ed.). (1999). Democracy and trust. New York: Cambridge University Press.

Winter, G., Vogt, C. A., \& McCaffrey, S. (2004). Examining social trust in fuels management strategies. Journal of Forestry, 102(6), 8-15.

Zucker, L. (1986). Production of trust: Institutional sources of economic structure, 1840-1920. Research in Organizational Behavior, 8, 53-11. 
This text taken from Human Ecology Review Volume 21, Number 1, 2015, published 2015 by ANU Press, The Australian National University, Canberra, Australia. 